\title{
A terapia renal substitutiva em São Paulo: uma análise a partir da economia política da saúde
}

\author{
Antonio PESCUMA JUNIOR ${ }^{(1)}$ \\ Aylene BOUSQUAT ${ }^{(1)}$
}

${ }^{(1)}$ Faculdade de Saúde Pública, Universidade de São Paulo - USP, São Paulo, SP, Brasil.

Recebido: 28 jan 2019 Aceito: 10 fev 2019

Autor de correspondência: antoniopescuma@usp.br

Conflito de interesses: Os autores declaram não haver nenhum interesse profissional ou pessoal que possa gerar conflito de interesses em relação a este manuscrito.

\section{Resumo}

A terapia renal substitutiva (TRS) é utilizada por uma quantidade elevada de pacientes em tratamento contínuo, demandando montantes financeiros crescentes do Sistema Único de Saúde - SUS. Objetivo - explorar e compreender, a partir das contribuições da Economia Política da Saúde - EPS, os processos econômicos, políticos e sociais envolvidos na oferta da TRS no estado de São Paulo. Métodos - a partir do referencial teórico da EPS, foi realizado estudo de caso sobre a TRS no estado de São Paulo mediante a investigação da dimensão industrial, da política e a de proteção social. Com relação a dimensão industrial, a Saúde está inserida em um complexo conjunto de empresas, fornecedores e pessoas, desempenhando um papel importante na economia; A Oferta: máquinas, tecnologias associadas e incorporadas, inovações, drogas utilizadas, financiamento, aberturas de clínicas e incorporações. Foram construídos indicadores com base em dados secundários relacionados as Autorizações para Procedimentos de Alta Complexidade, ao Sistema de Gerenciamento da Tabela de Procedimentos, Medicamentos, Órteses, Próteses e Meios Auxiliares de Locomoção do SUS e ao Cadastro Nacional de Estabelecimentos de Saúde. A escala da análise foram as 17 redes Regionais de Atenção Saúde em São Paulo. Com relação a dimensão política e social, foram realizadas entrevistas com atores chaves. Procedeu-se inicialmente a leitura livre da entrevista, na sequencia forma identificados os núcleos temáticos de interesse da pesquisa. A dimensão política da Saúde: A política de Saúde incorpora diversas instituições, com diferentes atores: provedores, usuários, profissionais, pagadores e governantes; análise de Portarias, o papel das multinacionais, considerações sobre o público e o privado no segmento. A dimensão da Saúde como proteção social: a presença da política de Saúde nos sistemas de Saúde introduziu o direito à Saúde. O cuidado e o acesso do paciente renal crônico aos serviços de diálise. Resultados - $\mathrm{Na}$ dimensão industrial, foi constatado que apesar do elevado gasto, a tecnologia na diálise apresenta somente inovações incrementais. A oferta de máquinas em 2017 por 10.000 habitantes foi superior a do ano de 2008 em todas as regiões de saúde. O gasto para a diálise cresceu no período de 2008 a 2017. Houve crescimento de $37 \%$ na produção de procedimentos dialíticos ao longo de 2008 a 2017. Com relação aos turnos, $92 \%$ das clínicas operam com menos do que três 
turnos de atividade, tendo capacidade ociosa. A participação dos prestadores de serviços é de $2 \%$ para os prestadores de serviço municipais, $9 \%$ para os estaduais, $53 \%$ para os privados lucrativos e $35 \%$ para os privados sem fins lucrativos (filantrópicos). O custo é de $75 \%$ com filtros hemodialisadores importados, tendo elevado impacto no financiamento do SUS. Com a abertura do mercado da saúde ao capital estrangeiro, sancionada pelo governo através da Lei 13.097/2015, identificou-se a compra de clínicas privadas de diálise por empresas estrangeiras que pertencem a cadeia produtiva da dialise, em uma estrutura de mercado oligopolista. Com relação a dimensão política, não se observou a configuração de um conjunto de políticas públicas para o segmento. Por fim, com relação a dimensão de proteção social, há um acesso desigual aos serviços. Conclusões Verificou-se que a diálise está inserida em um cenário de extrema dependência produtiva para sua operacionalização, sendo que todos os insumos e equipamentos são importados. É notória a presença de empresas multinacionais no segmento da diálise, com maior poder de barganha na composição dos preços dos produtos ofertados ao segmento, delineando-se um processo inflacionário e um forte impacto nos gastos. O SUS financia esta área da saúde, seria importante a indução do parque produtivo nacional para a produção de filtros, mas, no entanto, este movimento ainda não foi concretizado. Para complementar, as multinacionais começam a adquirir as clínicas, em um processo de liquidação dos serviços de diálise, que pode ter implicações futuras no acesso aos pacientes SUS dependentes. Torna-se uma tarefa complexa manter os recursos fiscais dentro de um equilíbrio, com a satisfação plena das demandas sociais, sendo o financiamento sempre insuficiente frente as demandas reais dos segmentos que envolvem a seguridade social, incluindo a saúde. Portanto, dentro desta restrição de recursos financeiros para a saúde, as metodologias de Avaliação Econômica são utilizadas com frequência, com o objetivo fundamental de analisar alternativas existentes para o uso de insumos e tecnologias em um ambiente com restrição orçamentária. No entanto, apesar de serem importantes, tais estudos possui um escopo microeconômico da realidade e determinístico, sendo de extrema importância a contribuição de um novo referencial teórico denominado como Economia Política da saúde. Nesta pesquisa, a Economia Política da Saúde com as suas três dimensões, a industrial, a política e a de proteção social, contribuiu para o entendimento de um segmento de elevado gasto representado pela diálise. Foi estudada a dimensão industrial, que compreende o Complexo Econômico-Industrial da Saúde - CEIS, definido como um sistema produtivo que abrange os subsistemas de base industrial (química, biotecnológica, mecânica, eletrônica e de materiais) e de serviços. Tal estudo foi de extrema importância, por identificar que a diálise está inserida em um cenário de extrema dependência produtiva. A saúde apresenta um elevado déficit na sua balança comercial, mais de 11 bilhões em 2013, uma expressão direta de um volume de importações superior ao quantum de exportações no segmento da saúde como um todo. 
Descritores: Financiamento da Assistência à Saúde; Política de Saúde; Política

Pública; Terapia de Substituição Renal. 